\title{
A Novel Miniature Wind Generator for Wireless Sensing Applications
}

\author{
Dibin Zhu, Steve Beeby, John Tudor, Neil White and Nick Harris \\ Electronic Systems and Devices Group, School of Electronics and Computer Science \\ University of Southampton \\ Southampton UK \\ dz@ecs.soton.ac.uk,spb@ecs.soton.ac.uk,mjt@ecs.soton.ac.uk,nmw@ecs.soton.ac.uk, nrh@ecs.soton.ac.uk
}

\begin{abstract}
This paper describes a novel miniature wind generator for wireless sensing applications. The generator consists of an aerofoil that is attached to a cantilever spring. The airflow over the aerofoil causes the cantilever to bend, the degree of bending being a function of the lift force from the aerofoil and the spring constant. As the cantilever deflects, the flow of air is reduced by a bluff body and the lift force therefore decreases causing the cantilever to spring back. The aerofoil is hence exposed to the full airflow again and the cycle is repeated. When the frequency of the movement matches the resonant frequency of the structure, the aerofoil has the maximum displacement. A permanent magnet is fixed on the aerofoil and a coil is attached to the base of the generator. The movement of the aerofoil causes the magnetic flux cutting the coil to change, which generates electrical power. The device has dimensions of $12 \mathrm{~cm} \times 8 \mathrm{~cm} \times 6.5 \mathrm{~cm}$. Experiments have shown that the generator can operate at wind speeds as low as $2.5 \mathrm{~m} \cdot \mathrm{s}^{-1}$ with a corresponding electrical output power of $470 \mu \mathrm{W}$. This is sufficient for periodic sensing and wireless transmission. When the wind speed is $5 \mathrm{~m} \cdot \mathrm{s}^{-1}$, the output power is $1.6 \mathrm{~mW}$.
\end{abstract}

\section{INTRODUCTION}

Energy harvesting for powering wireless sensor nodes from the ambient environment has drawn considerable attention over the last decade. Some possible energy sources include photonic energy [1], thermal energy [2], mechanical energy [3] and wind energy [4]. For wind energy harvesting, existing methods include wind turbines [4], windbelt generators [5] and flapping piezoelectric generators [6], [7], [8]. However, they all have certain drawbacks that make them unsuitable for powering wireless sensor nodes. The wind turbine is the most commonly used method for wind energy harvesting, but the efficiency of conventional turbines reduces with size, due to the increased effect of friction losses in the bearings and the reduced surface area of the blades. Analysis of miniature turbines predicts a power output of 6 $\mu \mathrm{W} \cdot \mathrm{cm}^{-2}$ at $1 \mathrm{~m} \cdot \mathrm{s}^{-1}$ and to achieve $300 \mu \mathrm{W}$ at $0.5 \mathrm{~m} \cdot \mathrm{s}^{-1}$ would require a rotor diameter of $22 \mathrm{~cm} \mathrm{[9].} \mathrm{Furthermore,} \mathrm{rotating}$ components such as bearings suffer from fatigue and wear, especially when miniaturised and are not capable of operating unattended for 25 years [9]. The micro windbelt generator (13 $\mathrm{cm} \times 3 \mathrm{~cm} \times 2.5 \mathrm{~cm}$ ) has an output power over $2 \mathrm{~mW}$ at wind speeds higher than $5.5 \mathrm{~m} \cdot \mathrm{s}^{-1}$ but its output power reduces significantly $(<200 \mu \mathrm{W})$ at low wind speeds $\left(<3.5 \mathrm{~m} \cdot \mathrm{s}^{-1}\right)$ [5]. In addition, the windbelt generator can be extremely noisy during operation. The flapping piezoelectric generator requires a very flexible piezoelectric material so that the power output is very low due to the poor piezoelectric strain coefficient of existing materials. Li et al [6] investigated a wind energy harvester consisting of a flexible cantilever based on PVDF. Their device produced an output power of $1.8 \mu \mathrm{W}$ at a wind speed of $3.5 \mathrm{~m} \cdot \mathrm{s}^{-1}$. Ertuk et al [8] reported a wind generator with an improved flexible piezoelectric material, a Macro Fiber Composite (MFC). An electrical power output of $10.7 \mathrm{~mW}$ was delivered to a $100 \mathrm{k} \Omega$ load at a linear flutter speed of $9.3 \mathrm{~m} \cdot \mathrm{s}^{-1}$ in their test. However, the output power at lower wind speeds was not reported. The purpose of our research programme was to evaluate the design and performance of a miniature wind generator capable of producing a useful amount of output power for wireless sensor nodes $(>100 \mu \mathrm{W})$ at the lowest wind speed possible.

In this paper, a novel patented cantilever-based electromagnetic wind generator is reported [10]. Operation principles are first presented followed by design and optimization of the generator. Finally, the test results are presented and discussed. The generator was designed to work in a vertical duct. In the experimental tests, the generator was placed vertically in a wind tunnel in which air was blown downwards.

\section{PRINCIPLES}

\section{A. Oscillation under Air Flow}

The device has an aerofoil attached to a cantilever spring, which is clamped at one end as shown in Fig. 1(a). There is an initial downward displacement of the aerofoil due to gravity. The air flowing over the aerofoil causes the cantilever to bend as shown in Fig. 1(b), the degree of 
bending being a function of the lift/drag force from the aerofoil and the spring constant. Under normal conditions this is a static deflection, but this can become dynamic by causing the lift force to be asymmetric with deflection about the zero axis, i.e. to vary with the direction of deflection of the cantilever. This is achieved by placing a bluff body, which produces vortices, below the cantilever. As the cantilever deflects, the bluff body reduces the flow of air and the lift force reduces, hence causing the cantilever to operate primarily under inertial effects and so spring back as shown in Fig. 1(c). When the cantilever springs back to the initial position, the aerofoil is exposed to the full airflow again, energy is once again extracted from the airflow and the cycle is repeated. By appropriate design and positioning of the bluff body, and by tuning the resonant frequency of the cantilever spring, the system resonates.

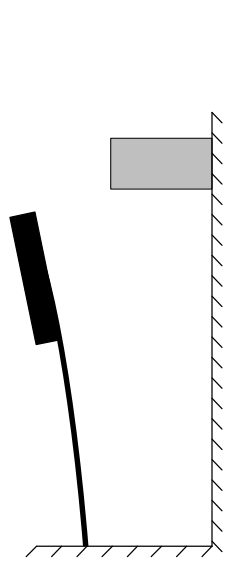

(a) No air flow

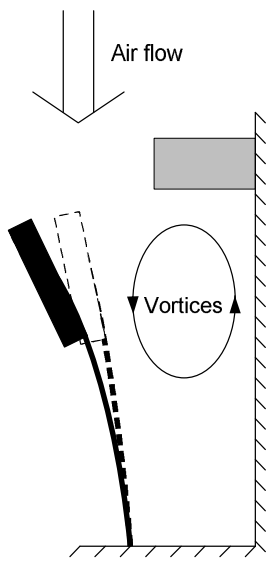

(b) Cantilever bent due to air flowing

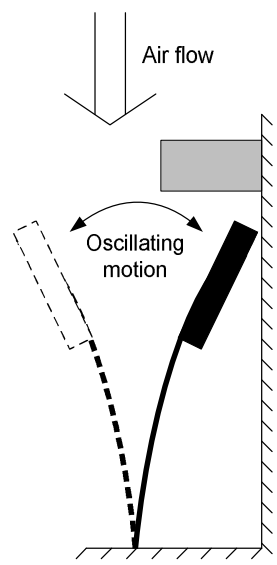

(c) Cantilever sprung back
Figure 1. Operational principle of the device.

\section{B. Electromagnetic Transducer}

The electromagnetic transducer used in the device is shown in Fig. 2. A cylinder magnet is attached to the aerofoil that is connected to the cantilever spring. A static coil is placed underneath the magnets. The magnet moves up and down with the aerofoil due to the air flow, which causes magnetic flux travelling through the static coil to change, thus an electric current is produced.



Figure 2. Electromagnetic transducer.

\section{DESIGN OF THE DEVICE}

The performance of the device depends on the movement of the aerofoil due to the air flow, which is a function of the following parameters and depicted in Fig. 3.

$\alpha$ : Angle of elevation.

$h$ : Height of the bluff body.

$d$ : $\quad$ Distance between the bluff body and the aerofoil.

In addition, the effect of the cross section of the aerofoil on the oscillation of the aerofoil was also investigated.

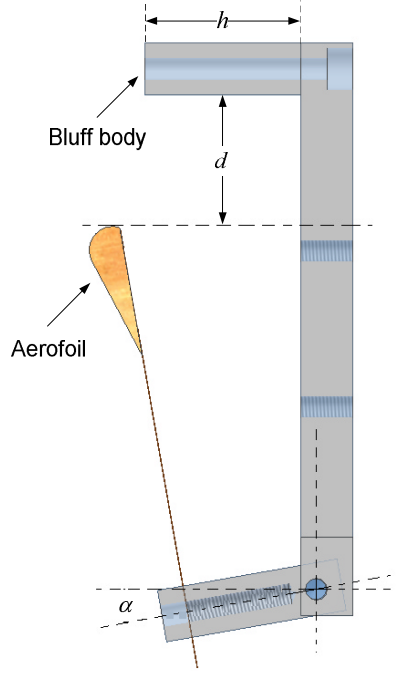

Figure 3. Schematic view of the aerofoil (transducer not included).

The dimensions of the cantilever were $50 \mathrm{~mm} \times 18 \mathrm{~mm} \times$ $0.2 \mathrm{~mm}$. It was made of beryllium copper. The aerofoil, made of balsa wood, was $25 \mathrm{~mm}$ wide and had a span of $80 \mathrm{~mm}$. The overall mass on the aerofoil was $27.7 \mathrm{~g}$.

\section{A. Angle of Elevation}

The angle of elevation was investigated with various combinations of $h$ and $d$. $h$ was set between 10 and $25 \mathrm{~mm}$ and $d$ between $5 \mathrm{~mm}$ and $20 \mathrm{~mm}$. It was found that irrespective of $h$ and $d$, when $\alpha$ is less than $10^{\circ}$ or larger than $20^{\circ}$, the aerofoil did not oscillate. If $\alpha$ is between $10^{\circ}$ and $20^{\circ}$, the minimum wind speed at which the aerofoil starts swinging varies from $2 \mathrm{~m} \cdot \mathrm{s}^{-1}$ to $3 \mathrm{~m} \cdot \mathrm{s}^{-1}$. Experimentally, the optimum angle of elevation was found to be approximately $15^{\circ}$.

\section{B. Effect of Bluff Body}

The angle of elevation was set at $14.5^{\circ}$ when investigating the effect of the bluff body on the aerofoil. Fig. 4 compares the minimum wind speeds at which the aerofoil starts swinging with the variation of distance between the aerofoil and the bluff body with different heights. It was found that with increasing gap between the bluff body and the aerofoil, the starting wind speed reduced no matter what the height of the bluff body. The optimum height of the bluff body was found to be $30 \mathrm{~mm}$. When the bluff body was placed $20 \mathrm{~mm}$ (or further) away from the aerofoil, the aerofoil was able to start swinging at lower wind speeds. 


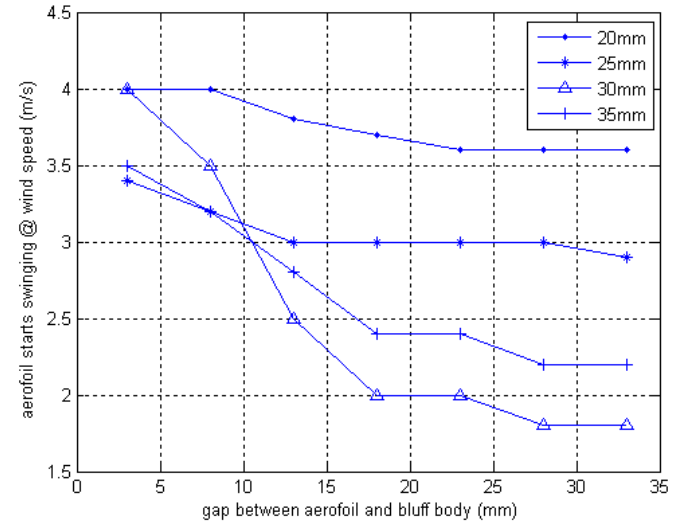

Figure 4. Comparisons of the minimum wind speeds at which the aerofoil starts swinging with variation of distances between the aerofoil and bluff body with different heights

\section{Cross section of aerofoil}

Various designs of cross section were investigated to find the best aerofoil, which provided the maximum lift force for a given size. However, it was found experimentally that the generator was able to swing at low wind speed regardless of the aerofoil cross section as long as the angle of elevation as well as the size and position of the bluff body were properly adjusted. For simplicity and low cost, a rectangular block was used to replace the aerofoil. Its dimensions were $80 \mathrm{~mm} \times 25$ $\mathrm{mm} \times 6 \mathrm{~mm}$.

\section{Final Device}

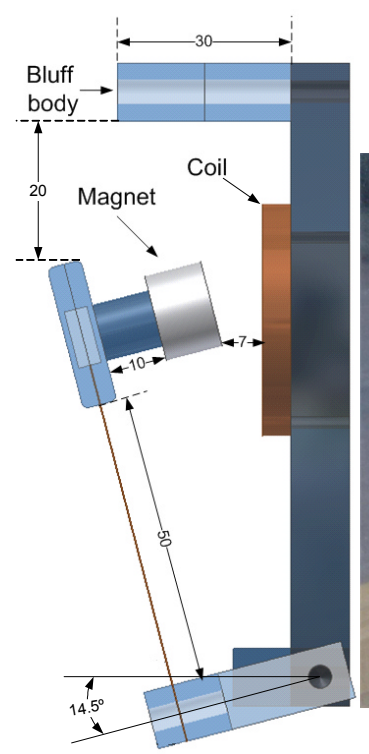

(a)

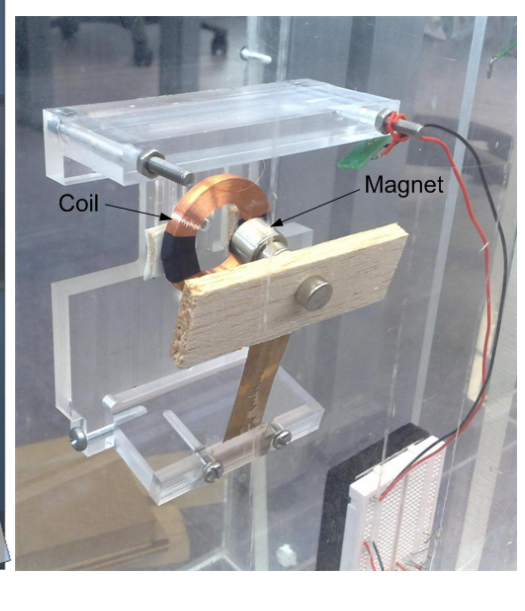

(b)
Figure 5. Final device (a) Schematic view with dimensions (in $\mathrm{mm}$ ). (b) Photo of the actual device.

Fig. 5 shows the schematic view of the device with key dimensions, together with a photograph of the actual device. The cantilever was made of Beryllium Copper $(\mathrm{BeCu})$ and had dimensions of $50 \mathrm{~mm} \times 18 \mathrm{~mm} \times 0.2 \mathrm{~mm}$. The cylinder magnet was made of NdFeB-38H. Its diameter was $15 \mathrm{~mm}$ and its height was $10 \mathrm{~mm}$. The magnet was fixed $10 \mathrm{~mm}$ below the aerofoil and was $7 \mathrm{~mm}$ away from the fixed coil. The coil was wound using $60 \mu \mathrm{m}$ thick copper wire. Its outer and inner diameters were $24 \mathrm{~mm}$ and $40 \mathrm{~mm}$, respectively. The thickness is $5 \mathrm{~mm}$. The coil had a resistance of $4.7 \mathrm{k} \Omega$ and approximately 7800 turns. Both the base of the generator and the bluff body were made of acrylic. The overall dimensions of the device were $12 \mathrm{~cm} \times 8 \mathrm{~cm} \times 6.5 \mathrm{~cm}$.

\section{TEST AND RESUlts}

\section{A. Wind Tunnel}

Fig. 6 shows the wind tunnel used in the test. To generate laminar air flow in the tunnel, a centrifugal fan was used. The wind tunnel had an opening of $30 \mathrm{~cm} \times 22.5 \mathrm{~cm}$. The fan can provide the air flow of up to $10 \mathrm{~m} \cdot \mathrm{s}^{-1}$. The wall of the wind tunnel was made of acrylic so that oscillation of the generator can be observed in the tests.

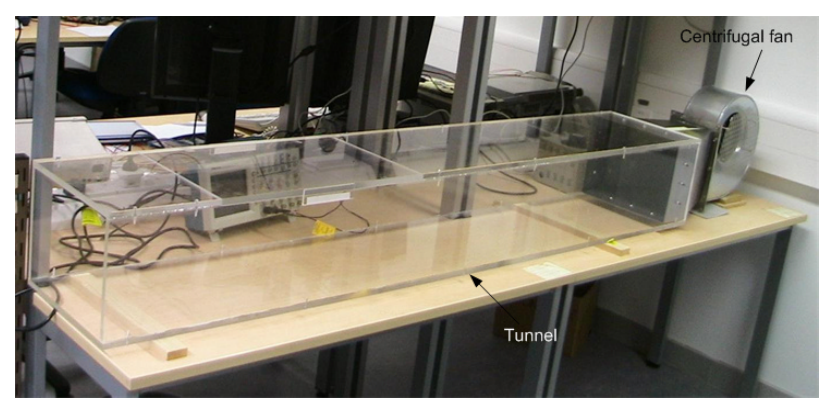

Figure 6. Wind tunnel when placed horizontally.

\section{B. Test Setup}

The generator was screwed on a plate, which was placed vertically in the wind tunnel as shown in Fig. 7. At each wind speed, the generator was connected to various resistive loads to find the optimum load and optimum output power.

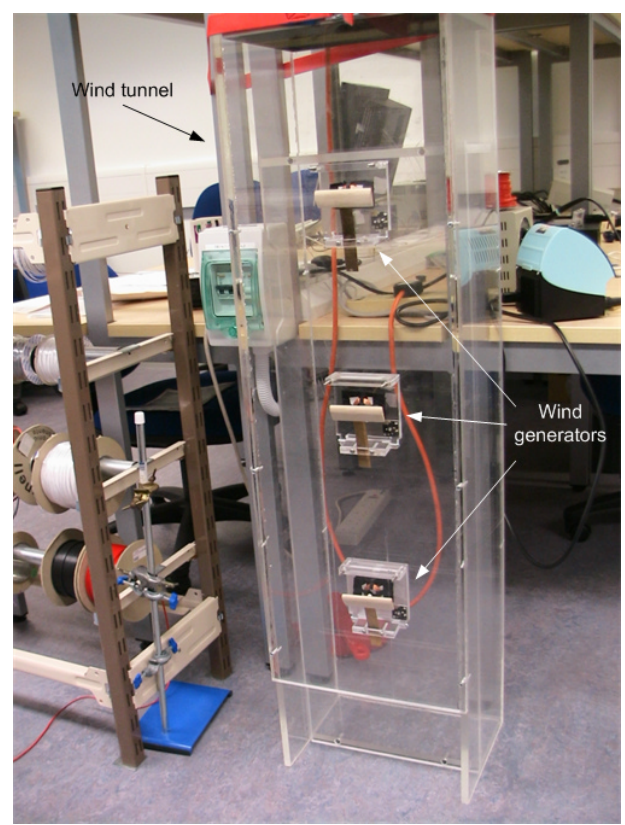

Figure 7. Generators in the wind tunnel. 


\section{Results}

Fig. 8 shows the output power of the generator for a variety of resistive loads. It is found that for increasing wind speeds, the optimum value of load resistance decreased. The optimum output RMS power of the generator with variation of wind speed is shown in Fig. 9. The generator starts working from a wind speed of $2.5 \mathrm{~m} \cdot \mathrm{s}^{-1}$ when it produces an output power of $470 \mu \mathrm{W}$, which is sufficient to power a general sensor node for periodic sensing and wireless transmission. The output power increases linearly with the wind speed.

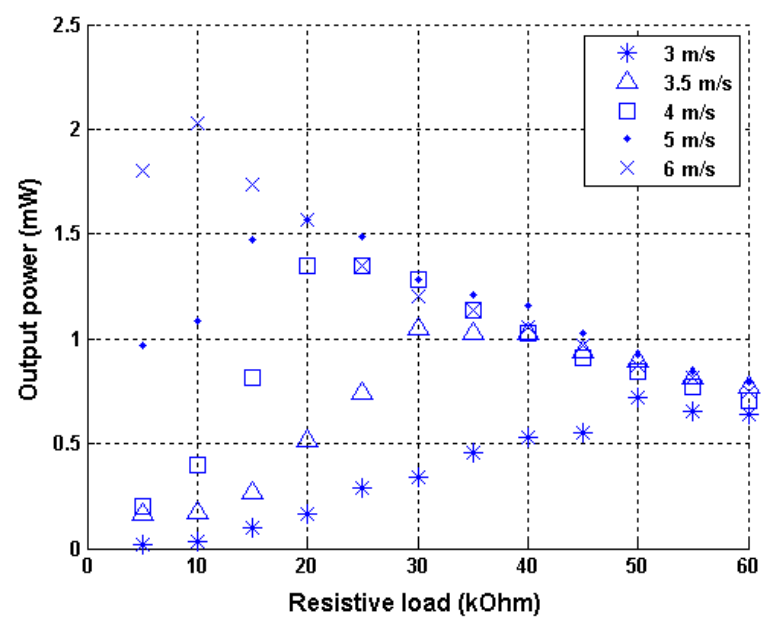

Figure 8. Output power of the generator vs. resistive loads.

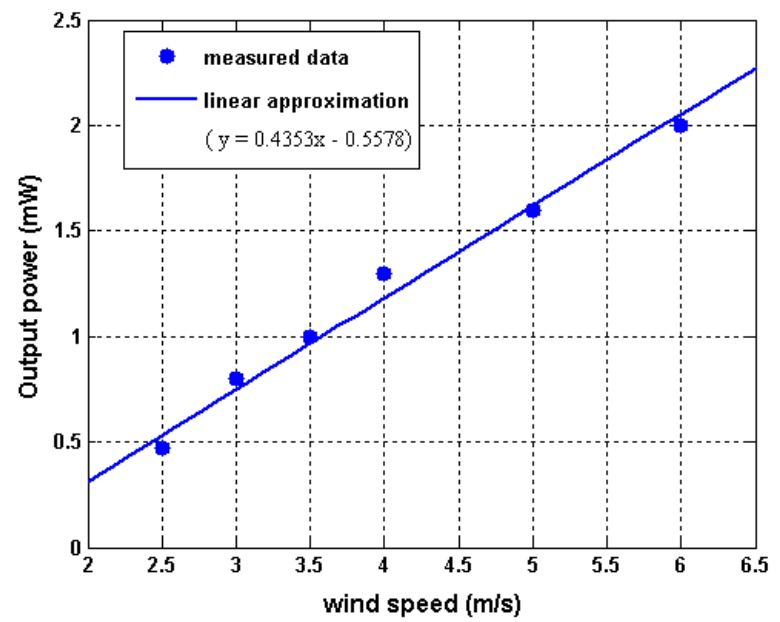

Figure 9. Output power at the optimum loads of the generator vs. wind speed.

\section{CONCLUSIONS AND FUtURE RESEARCH}

This paper describes a novel electromagnetic wind generator, which was designed to work in a vertical duct and was tested in a vertical wind tunnel. It has dimensions of 12 $\mathrm{cm} \times 8 \mathrm{~cm} \times 6.5 \mathrm{~cm}$. Experimentally, it started working at a low wind speed of $2.5 \mathrm{~m} \cdot \mathrm{s}^{-1}$ and produced a corresponding average output power of $470 \mu \mathrm{W}$.
In future research, a power conditioning circuit will be developed to use the generator to charge a super capacitor and to power wireless sensor nodes. Further improvements will be made to increase the output power of the device and reduce the minimum wind speed at which the generator starts working. In addition, the generator was designed to work vertically. Due to gravity, the initial displacement of the mass is different when the device is placed horizontally. Both elevation angle and bluff body will be reconfigured to suit horizontal applications.

For the flapping wind generator, one major drawback is that there is no mechanism to limit the displacement of the tip mass. If the wind speed becomes high $\left(>10 \mathrm{~m} \cdot \mathrm{s}^{-1}\right)$, the displacement of the mass can be very large, which may reduce the lifespan of the device. One potential solution is to control the electrical damping by varying the electrical load. To achieve this, the transducer must have high coupling. However, if the electromagnetic coupling is too high, the generator may not work at low wind speed. There is thus a tradeoff between degree of electromagnetic coupling and minimum working wind speed. Further investigation will be done to find a suitable transducer to enable damping control to limit the mass displacement while not increasing the minimum starting wind speed.

\section{ACKNOWLEDGMENT}

The authors of this paper would like to thank D4 Technology Ltd (www.d4technology.co.uk) for their technical and financial support in this research.

\section{REFERENCES}

[1] B. C. Norman "Power options for wireless sensor networks," IEEE Aerospace and Electronic Systems Magazine, vol. 22(4), pp. 14-17, April 2007.

[2] David Michael Rowe, "Thermoelectric waste heat recovery as a renewable energy source," International Journal of Innovations in Energy Systems and Power, vol. 1(1), pp. 13-23, November 2006.

[3] S. P. Beeby, M. J. Tudor, and N. M. White, "Energy harvesting vibration sources for microsystems applications," Measurement Science and Technology, vol. 17, pp. 175-95, December 2006.

[4] G. M. Joselin Herberta, S. Iniyanb, E. Sreevalsanc, and S Rajapandian, "A review of wind energy technologies," Renewable and Sustainable Energy Reviews, vol. 11, pp. 1117-1145, August 2007.

[5] http://www.humdingerwind.com, accessible at $28^{\text {th }} \mathrm{July}, 2010$.

[6] S. Li, and H. Lipson, "Vertical-Stalk Flapping-Leaf Generator For Parallel Wind Energy Harvesting," Proceedings of the ASME/AIAA 2009 Conference on Smart Materials, Adaptive Structures and Intelligent Systems, SMASIS 2009.

[7] L. Tang, M. P. Paidoussis, and J. Jiang, "Cantilevered flexible plates in axial flow: Energy transfer and the concept of flutter-mill," Journal of Sound and Vibration, vol. 326, pp. 263-276, September 2009.

[8] A. Erturk, W. G. R. Vieira, C. De Marqui, Jr., and D. J. Inman, "On the energy harvesting potential of piezoaeroelastic systems," Applied Physics Letters, vol. 96, 184103, May 2010.

[9] P. D. Mitcheson, E. M. Yeatman, G. K. Rao, A. S. Holmes, and T. C. Green, "Energy Harvesting From Human and Machine Motion forWireless Electronic Devices," Proc. of the IEEE, vol. 96(9), pp. 1457-1486, September 2008.

[10] M. J. Tudor, N. M. White, S. P. Beeby and N. R. Harris, "Generator for converting fluid energy to electrical energy," WO/2010/043617, PCT/EP2009/063349, April 2010. 